\title{
Sensitivity Analysis of Soil Liquefaction Potential
}

\author{
Fatima Ayad ${ }^{1}$, Abdelmalek Bekkouche ${ }^{2} \&$ Youcef Houmadi $^{2}$ \\ ${ }^{1}$ Department of Civil Engineering, Faculty of Technology, Aboubekr Belkaid University, Tlemcen, Algeria \\ ${ }^{2}$ Department of Civil Engineering, University Center of Ain Temouchent, Algeria \\ Correspondence: Fatima Ayad, Department of Civil Engineering, Faculty of Technology, Aboubekr Belkaid \\ University, Tlemcen, Algeria. Tel: 213-790-026-920. E-mail: f_ayad@ymail.com
}

Received: July 25, 2013 Accepted: September 7, 2013 Online Published: December 6, 2013

doi:10.5539/esr.v3n1p14 URL: http://dx.doi.org/10.5539/esr.v3n1p14

\begin{abstract}
Soil liquefaction is the source of several major damages during earthquakes on the material and human level. Several authors have studied the probability of liquefaction by in situ and laboratory tests and several models have been proposed to calculate the safety factor. But because of various uncertainties in performance function parameters, we adopted in this paper a reliability analysis that considers uncertainties of parameters and model uncertainties. We used the Monte Carlo simulation (MCS) to calculate the probability of failure to liquefaction based on standard penetration test SPT which soil's parameters are modeled by random variables.

The reliability results obtained show that the variability of soil's parameters has an important impact on the probability of liquefaction. A sensitivity analysis based on the coefficient of variation is presented to see the effect of each random variable on the probability of liquefaction.
\end{abstract}

Keywords: liquefaction, reliability, Monte Carlo simulation, probability

\section{Introduction}

In literature there are several approaches to evaluate the liquefaction potential of soil: cyclic stress approach (Seed \& Idriss, 1971), cyclic deformation approach (Dobry et al., 1982) and energetic approach (Law et al., 1990). These three methods are implemented in deterministic and probabilistic approaches. Actually, the estimation of liquefaction potential is a probabilistic problem rather than deterministic because of the uncertainties of parameters influencing liquefaction.

To calculate a probability we must choose a method for calculating the probability distribution function (PDF) of the response of the system or the probability of failure (pf). In this paper we used the Monte Carlo simulation (MCS) method which is known by several authors. Popescu (1995) used this method to characterize the spatial variability of soil parameters and to evaluate the liquefaction risk, Na et al. (2009) to study the probabilistic nature of the seismic response of a port, and Johari et al. (2012) to calculate the probability density function of the liquefaction safety index.

In the aim of studying the impact of the performance function parameters which is modeled by random variables on the probability of failure, a sensitivity analysis was presented and discussed. Results show that the maximal acceleration, magnitude of the earthquake and the SPT blow counts has an important impact on the seismic response.

\section{Deterministic Approach}

Several approaches have been proposed to evaluate the liquefaction potential; in this article we use the cyclic stress approach (Seed \& Idriss, 1971). This method has been adopted by several researchers (Çetin, 2000; Johari et al., 2012; Rezania et al., 2011; Juang et al., 2012; Lalita et al., 2012).

In this approach the cyclic stress ratio (CSR) for a moment magnitude of earthquake $\mathrm{Mw}=7.5$ is given by (Seed \& Idriss, 1971):

$$
C S R_{7.5}=0.65\left(\frac{\sigma_{v}}{\sigma_{v}^{\prime}}\right)\left(\frac{a_{\max }}{g}\right)\left(\frac{r_{d}}{M S F}\right)
$$


where $\sigma_{v}$ : is the total vertical soil stress, $\sigma_{v}^{\prime}$ : effective stress, $a_{\max }$ : the maximum horizontal acceleration of the earthquake at the soil surface, $r_{d}$ : is the reduction factor of the stress with depth. There are several empirical relations related $r_{d}$ with depth. However the most commonly used formula was proposed by Seed and Idriss, (1971), is closed by Liao and Whitman, (1986) and expressed as:

$$
r_{d}=\frac{\left(1-0.4113 Z^{0.5}+0.04052 Z+0.001753 Z^{1.5}\right)}{1-0.4177 Z^{0.5}+0.05729 Z-0.006205 Z^{1.5}+0.00121 Z^{2}}
$$

With $\mathrm{Z}$ is the depth of soil.

Youd et al. (2001), Liao et al. (1988) have simplified this formula by the relationship (3)

$$
\begin{array}{ll}
r_{d}=1-0.00765 z & \text { for } z<9.15 m \\
r_{d}=1.174-0.0267 z & \text { for } 9.15 m<z \leq 20 m
\end{array}
$$

MSF: amplitude scale factor, it is calculated by the following Equation (Youd et al., 2001).

$$
M S F=\left(\frac{M_{w}}{7.5}\right)^{-2.56}
$$

To determine the CRR (which is the cyclic resistance ratio) using the SPT test, several models have been proposed: Youd et al. (2001), Idriss and Boulanger $(2006,2010)$. In this study we used only the approach proposed by Youd et al. (2001) defined by the following relationship:

$$
C R R=\frac{1}{34-N_{1.60 c s}}+\frac{N_{1.60 c s}}{135}+\frac{50}{\left(10 N_{1.60 c s}+45\right)^{2}}-\frac{1}{200}
$$

$N_{1.60 c s}$ : corrected SPT blow counts, because the ratio CRR increases by increasing the percentage of fines (Youd, 2001) and which therefore requires to correct the number of counts $\mathrm{N}_{1.60}$ by $\mathrm{N}_{1 .(60 \mathrm{cs})}$ defined by the Equation:

$$
N_{1.60 c s}=\alpha+\beta N_{1.60}
$$

$\alpha$ and $\beta$ are coefficients which depend on the fine contents as follows.

$$
\begin{aligned}
& \left\{\begin{array}{l}
\alpha=0 \\
\beta=1
\end{array} \quad \text { for } F C \leq 5 \%\right. \\
& \left\{\begin{array}{l}
\alpha=\exp \left(1.76-\left(190 / F C^{2}\right)\right) \\
\beta=\left(0.99+\left(F C^{1.5} / 1000\right)\right)
\end{array} \text { for } 5 \%<F C<35 \%\right. \\
& \begin{cases}\alpha=5 & \text { for } F C \geq 35 \% \\
\beta=1.5 & \end{cases}
\end{aligned}
$$

In the deterministic approach the safety factor $(\mathrm{Fs})$ is defined by $F_{s}=\frac{C R R}{C S R}$. The soil is liquefiable if the safety factor $F_{s} \leq 1$, and it is non-liquefiable if $F_{s}>1$. But because of uncertainties included in the model and used parameters, the fact that $F_{s}>1$ does not always correspond to a non-liquefaction, and $F_{s} \leq 1$ does not always correspond to a liquefaction (Juang et al., 2008).

\section{Probabilistic Approach}

In the literature we find that the probabilistic method has been widely used for the evaluation of liquefaction potential of soils (Cetin et al., 2004; Idriss \& Boulanger., 2010; Juang et al., 2012; Bhattacharya \& Goda, 2013). But most of these authors use probabilistic models based on statistical analyzes of historical cases. Using these models who defined parameters influencing liquefaction potential only by the mean value, thus the probability may be have uncertainties, why we should always adopt a reliability analysis. In this analysis we can consider different sources of uncertainty considered by Kulhawy (1992). But in this study we will only consider the parameter's uncertainties and model's uncertainties.

The procedure for making a reliability analysis that considers both types of uncertainties is described as follows: 
- Determination of the limit state function;

- Define the mean and the standard deviation of each soil's parameter;

- Calculate the correlation matrix for these parameters;

- And finally, calculate the probability of liquefaction.

\subsection{The Limit State Function}

To perform a reliability study, we must always begin with formulating the limit state function of the studied problem. In the case of liquefaction, called limit state function or performance function the function that separates the liquefiable region to the non-liquefiable region and it is expressed by Equation (8):

$$
G(X)=C R R-C S R=0
$$

Because of uncertainties of the parameter formulating CSR and CRR, we modeled these parameters by random variables defined by the mean, standard deviation or coefficient of variation. To calculate CRR, we consider two random variables: N1. 60, and fine contents FC. To calculate CSR, we consider four random variables: $a_{\max }, M_{w}, \sigma_{v}^{\prime}, \sigma_{v}$.

Therefore $\mathrm{G}(\mathrm{X})$ is a function of 6 random variables expressed by:

$$
G(X)=C R R-C S R=G\left(N_{1,60}, F C, a_{\max }, M_{w}, \sigma_{v}, \sigma_{v}^{\prime}\right)
$$

If we take into account the uncertainty of the model, the performance function is defined by (Juang et al., 2008):

$$
G(X)=c_{1} C R R-C S R=G\left(c_{1}, N_{1.60}, F C, a_{\max }, M_{w}, \sigma_{v}, \sigma_{v}^{\prime}\right)
$$

$\mathrm{c}_{1}$ : represents the model uncertainty of the limit state function.

The probability of liquefaction is estimated by calculating the integral defined by Equation (11)

$$
P_{f}=P(g(X) \leq 0)=\int_{g(X) \leq 0} f_{X}(X) d X
$$

With $f_{X}(X)$ is the probability density function of the random variables.

\subsection{Parameter Uncertainties of the Performance Function}

After defining the performance function, we must estimate the uncertainties of the parameters included in its formulation.

We must define the six random variables with the probability distributions. This involves estimating the mean and standard deviation if the variable is assumed to follow a normal or log-normal distribution.

Duncan (2000) suggested that the standard deviation of a random variable can be obtained either from a direct calculation of data, by an estimation based on the coefficient of variation (COV), or by an estimation based on the "rule of three-sigma" (Dai \& Wang, 1992).

For an estimation based on the coefficient of variation (the most commonly used parameter to define the parameter uncertainties and which is expressed by the ratio between the standard deviation and the mean) we can refer to the following table.

Table 1 .Coefficients of variation of input random variables

\begin{tabular}{cccc}
\hline Random variable & COV & References & Distribution \\
\hline $\mathrm{N}_{1.60}$ & $0.1 \quad 0.40$ & $\begin{array}{l}\text { Harr (1987); Gutierrez et al. } \\
(2003) ; \text { Phoon et Kulhaway }\end{array}$ & Normal \\
& $0.15-0.45$ & (1999) & \\
$\mathrm{F}_{\mathrm{C}}$ & $0.05-0.35$ & Jones et al. (2002) & Normal \\
$\sigma_{v}^{\prime}$ & $0.1-0.2$ & Gutierrez et al. (2003) & Normal \\
& $0.05-0.20$ & Juang et al. (1999) & Normal \\
$\sigma$ & $0.05-0.20$ & Juang et al. (1999) & Lognormal \\
$\mathrm{a}_{\max }$ & $0.1-0.2$ & Juang et al. (1999) & Normal \\
$\mathrm{M}_{\mathrm{w}}$ & $0.05-0.10$ & Juang et al. (1999) &
\end{tabular}


The estimation of the coefficient of variation of seismic parameters $\mathrm{a}_{\max }$ and $\mathrm{Mw}$ is based essentially on different inversions of seismograms recorded at different stations, and decreases with increasing magnitude due to less uncertain estimation of seismological parameters for large earthquake (Uzielly, 2004).

The COV of amax, may be greater than 0.5 (Haldar \& Tang, 1979), and for COVs (Mw), there is a relationship to calculate the variance of the magnitude (Moss, 2003).

$$
\sigma_{M_{w}}^{2} \cong 0.50-0.45 \log M_{w}
$$

\subsection{Correlation Matrix}

When we have several random variables, as in our case of liquefaction, the uncertainty of a parameter includes the uncertainty of the others. We express the dependence between random variables by correlation coefficient. In continuation of our work, we used the correlation coefficients determined empirically by Juang et al. 2008 and are based on an analysis of data in the databases of historical cases.

$$
\begin{array}{ccccccc} 
& N_{1.60} & F c & \sigma_{v}^{\prime} & \sigma_{v} & a_{\max } & M w \\
N_{1.60} & 1 & 0 & 0.3 & 0.3 & 0 & 0 \\
F c & 0 & 1 & 0 & 0 & 0 & 0 \\
\sigma_{v}^{\prime} & 0.3 & 0 & 1 & 0.9 & 0 & 0 \\
\sigma_{v} & 0.3 & 0 & 0.9 & 1 & 0 & 0 \\
a_{\max } & 0 & 0 & 0 & 0 & 1 & 0.9 \\
M w & 0 & 0 & 0 & 0 & 0.9 & 1
\end{array}
$$

The correlation coefficient between the uncertainty of the model and the other parameters is assumed to be 0 (Juang et al., 2008).

\subsection{Calculating the Probability of Liquefaction}

In literature there are several methods to calculate the probability of soil liquefaction. These methods are divided into two approaches:

Approximation method: FORM and SORM method (the reader can refer to Grifith and Fenton, 2007 for details) Simulations Method: Monte Carlo simulation (MCS), Importance Sampling simulation, Subset simulation. In this study we use Monte Carlo simulations that is based on performing a large number of simulations Ns (sampling) of random variables of the studied problem. For each simulation, the limit state function is calculated and we count the number of simulations leading to the failure Nsf.

$$
P_{f}=\int I(x) f(x) d x
$$

With I (xi) is an indicator function defined by:

$$
I(x)=\left\{\begin{array}{l}
1 \text { si } G(x) \leq 0 \\
0 \text { si } G(x)>0
\end{array}\right.
$$

The probability of failure $\mathrm{P}_{\mathrm{f}}$ can be estimated by the ratio between the number of simulations leading to rupture Nsf and the total number of sampling Ns.

$$
\widetilde{P}_{f}=\frac{N_{s f}}{N_{s}}=\frac{1}{N_{s}} \sum_{i=1}^{N_{s}} I\left(x_{i}\right)
$$

We can estimate the precision of Monte Carlo simulation method by calculating the coefficient of variation of the failure probability defined by Equation (14) that is inversely proportional to Ns. This implies that the sample size Ns in Monte Carlo simulation is very important to obtain a sufficiently reliable estimate of Pf

$$
\operatorname{COV}\left(\widetilde{P}_{f}\right)=\sqrt{\frac{1-P_{f}}{N_{s} \cdot P_{f}}}
$$

For a target coefficient of variation of the failure probability $\mathrm{COV}(\mathrm{Pf})$, the minimum number of samples Ns can be calculated from the following Equation. 


$$
N_{s}>\frac{1}{\operatorname{COV}^{2}\left(P_{f}\right)} \times\left(\frac{1}{P_{f}-1}\right)
$$

\section{Application}

The Example that we treat for deterministic and probabilistic analysis of liquefaction potential of soil for a magnitude $\mathrm{Mw}=7.4$ and acceleration $\mathrm{a}_{\max }=0.2 \mathrm{~g}$ is taken from a site in hyogoken-Nambu (Kobe) after an earthquake of magnitude $\mathrm{M}=6.9$ occurred on 16 January 1995 (Idriss \& Boulanger, 2010). The different parameters of soils are shown in Figure 1.
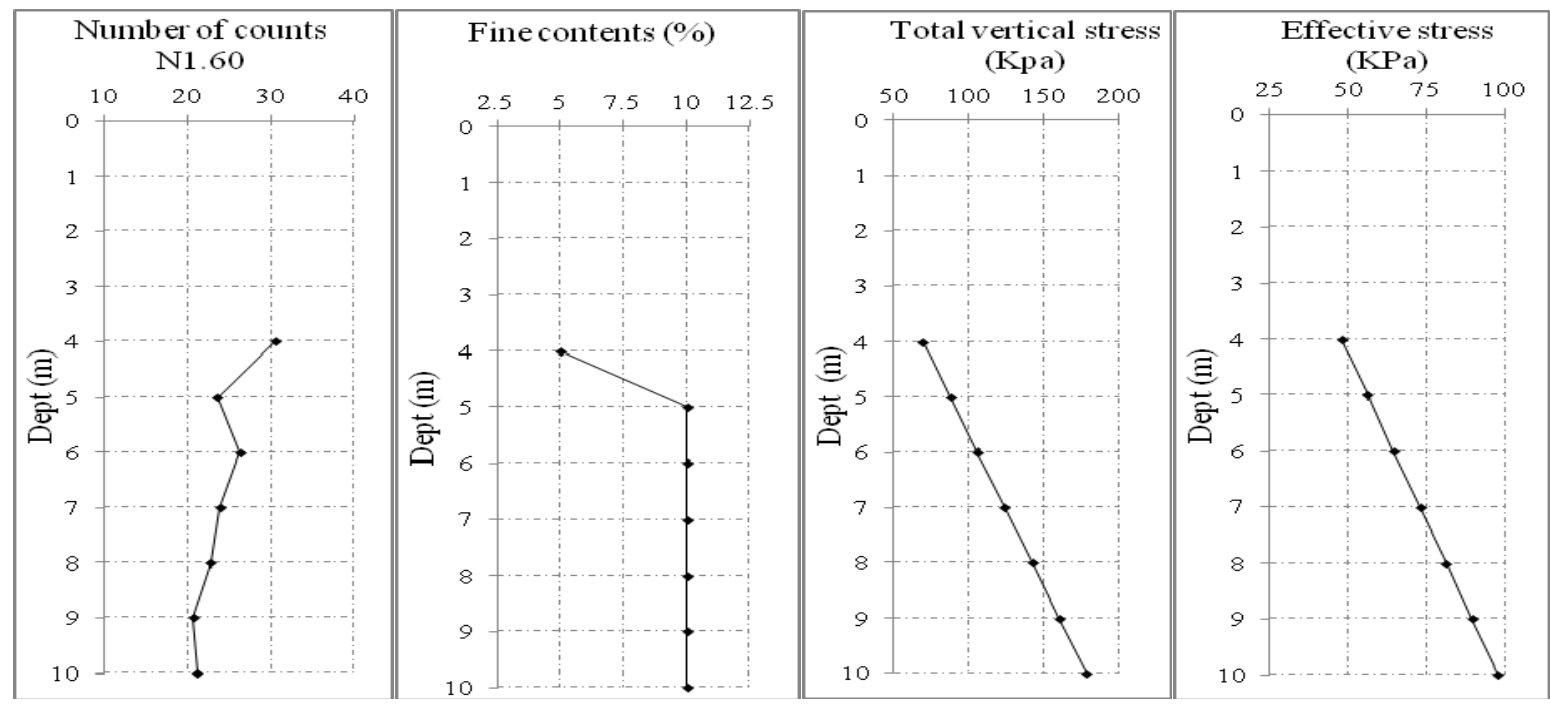

Figure 1. Distribution of soil parameters

\subsection{Deterministic Analysis}

In deterministic study of liquefaction, we calculate the safety factor Fs $=$ CRR/CSR for each depth. The soil is assumed to be liquefiable if the safety factor Fs $<1$, and it is non-liquefiable if Fs $>1$. The results are shown in Figure 2.

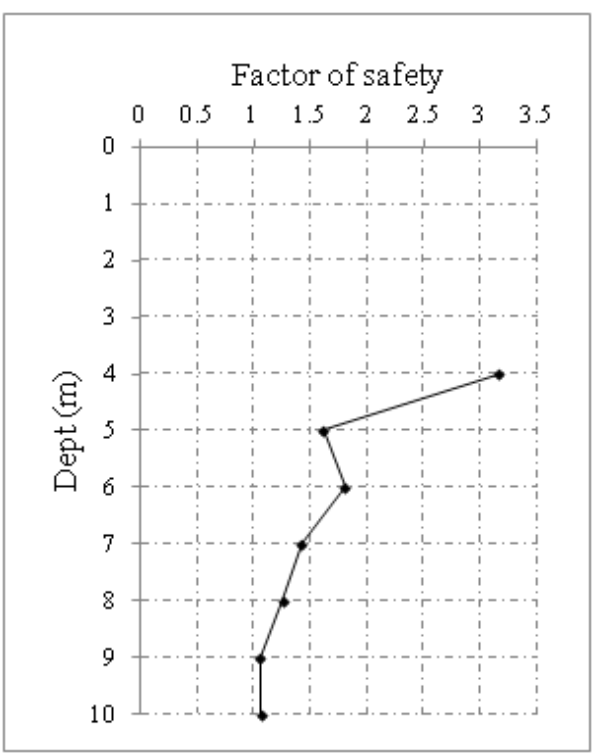

Figure 2. Safety factor against liquefaction 
We note from the results that the safety factor decreases with increasing soil depth and it is always greater than 1 . This result indicates that the soil is not susceptible to liquefaction. But because of different sources of uncertainty, we did a reliability-study to accurately calculate the probability of soil liquefaction.

\subsection{Estimating the Probability of Liquefaction}

A preliminary estimation of the probability of liquefaction can be obtained from empirical models. Juang et al 2008 gave the relationship between safety factor determined by a method based on the SPT test and the probability of liquefaction in the following way.

$$
P_{L}=\frac{1}{1+\left(\frac{F S}{1.05}\right)^{3.8}}
$$

In our site we compare the probability calculated by the relationship (Juang, 2008) with a reliability study taking into account-first uncertainties of random variables constituting the performance function and taking into account the model uncertainty.

To choose the number of Monte Carlo simulations required for convergence, Figure 3 and Figure 4 represent the estimation of the probability of liquefaction and its coefficient of variation respectively depending on the number of simulations at a depth of $9 \mathrm{~m}$.

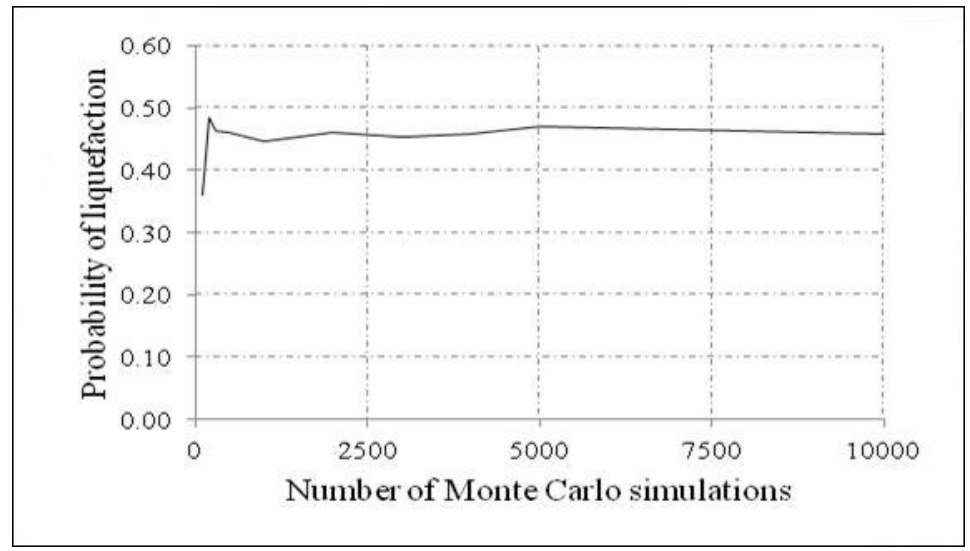

Figure 3. The probability of liquefaction depending on the number of simulations

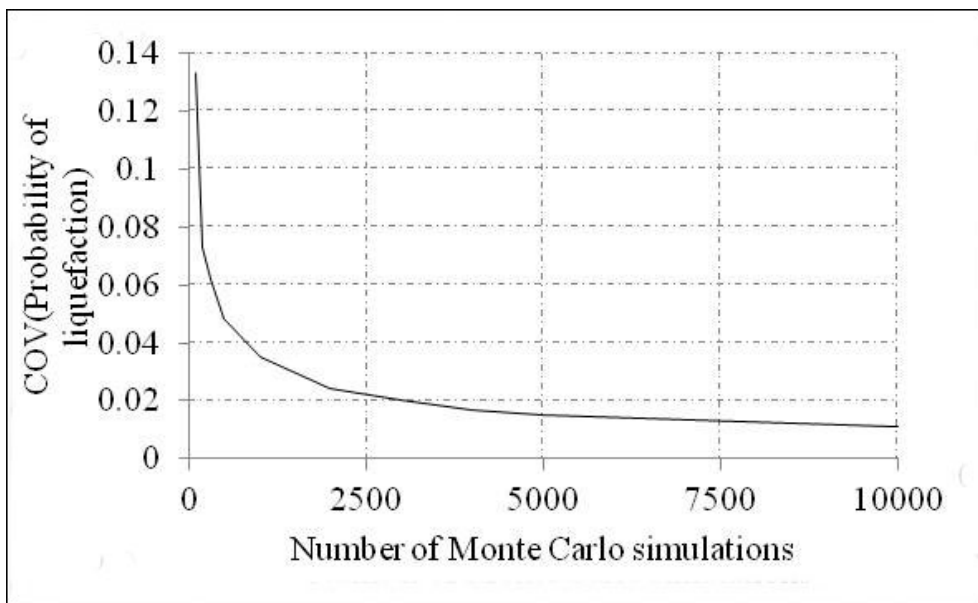

Figure 4. Coefficient of variation of the probability of liquefaction depending on the number of simulations

We note that the convergence is reached for a number of simulations close to 2500 for which the probability of liquefaction and its coefficient of variation become constant. But for more accurate result in subsequent calculations, 10000 simulations of random variables are generated. 
The probabilistic results obtained using 10000 Monte Carlo simulations throughout the mass of soil are shown in Figure 5 .

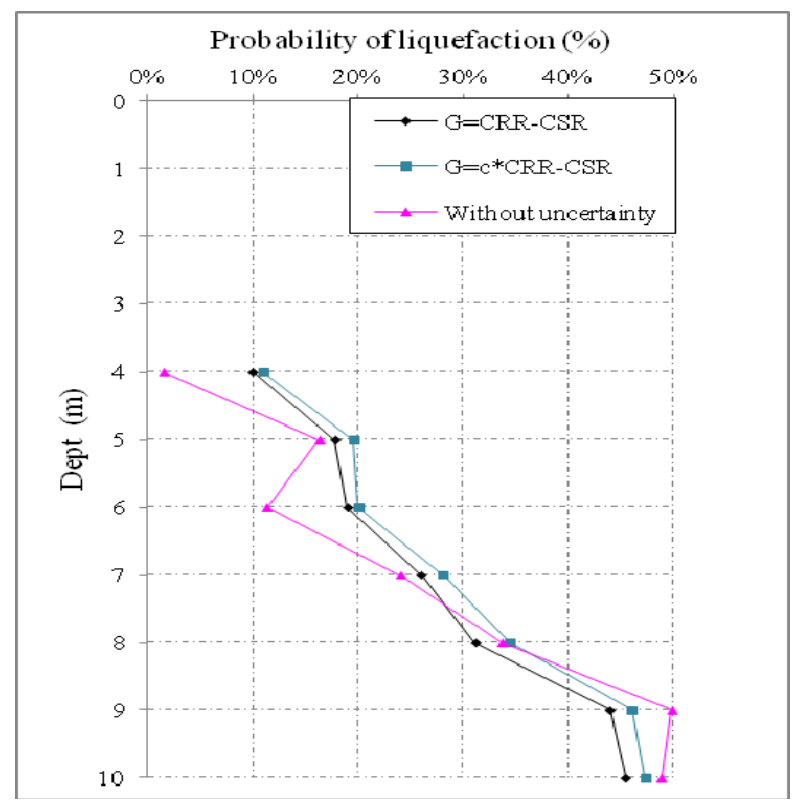

Figure 5. Probability of liquefaction calculated for different models

The first point that must be noted is that the probability of liquefaction calculated taking into account the uncertainties of random variables and Pf taking into account the uncertainties of the model are close. But is still seen as Pf taking into account the model errors is greater than Pf without taking into account these errors.

The second point is that the preliminary method of calculating Pf is not always valid. From this study, it was found that the estimation of Juang is only valid for a low factor of safety. What always requires to make a reliability study which takes into account uncertainties of the various parameters of the performance function and model uncertainties.

\section{Sensitivity Study}

In this section we present a sensitivity analysis based on the coefficient of variation to see the effect of the COV of each random variable on the response of the soil.

So we will vary the coefficient of variation of each parameter of the performance function taking into account the theoretical COV listed in the Table 1. For this we increase the COV of each parameter while the range of the other parameter is constant.

\subsection{Effect of the Coefficient of Variation of CRR Parameters}

In this section we present the effect of the resistance parameters on the probability of failure.

\subsubsection{Effect of the Coefficient of Variation of (N1.60)}

Figure 6 shows the effect of the coefficient of variation of $\left(\mathrm{N}_{1.60}\right)$ on the probability of liquefaction. It's indicates that the increase in $\operatorname{COV}\left(\mathrm{N}_{1.60}\right)$ from 10 to $25 \%$ increases the probability of liquefaction from 10 to $15 \%$. And increase in the $\operatorname{COV}\left(\mathrm{N}_{1.60}\right)$ form 20 to $30 \%$ also increases the likelihood of liquefaction in the same way.

If we take the limit of liquefaction the probability that $\mathrm{Pl}>35 \%$, we find that for the first case (COV (N1) $60=$ $10 \%)$, two depts only are liquefied $(9$ and $10 \mathrm{~m})$. In the second case $\left(\mathrm{COV}\left(\mathrm{N}_{1.60}\right)=25 \%\right) 3$ depts are liquefied $(8,9$ and $10 \mathrm{~m})$, and the third case $\left(\mathrm{COV}\left(\mathrm{N}_{1.60}\right)=40 \%\right)$ almost all layers are liquefied. 


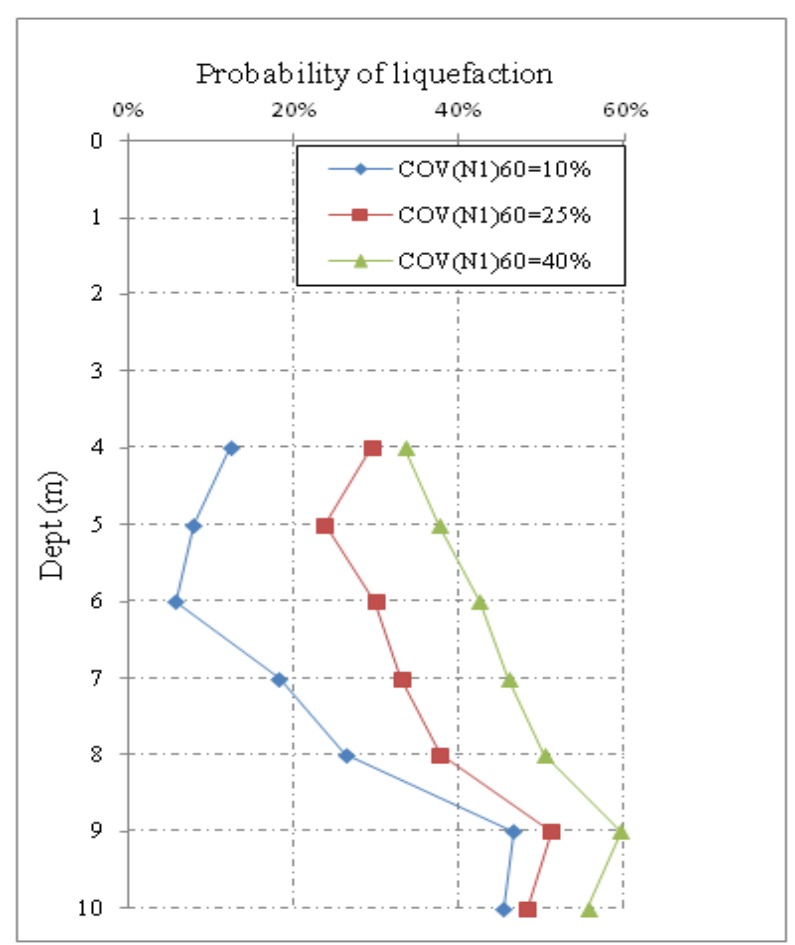

Figure 6. Effect of $\operatorname{COV}\left(\mathrm{N}_{1.60}\right)$ on liquefaction probability

The effect of $\operatorname{COV}\left(\mathrm{N}_{1.60}\right)$ decreases with increasing the depth, because in the déteministic study it was found that the safety factor FS decreases with increasing depth. It's indicates that the effect of $\operatorname{COV}\left(\mathrm{N}_{1.60}\right)$ is more importante for high factor of safety, and it's effect decreses by the decresase of the safety factor.

\subsubsection{Effect of $\mathrm{COV}(\mathrm{Fc})$}

Figure 7 show the effect of the coefficient of variation of fine contents on the probability of liquefaction. For increasing $\mathrm{COV}(\mathrm{Fc})$ from $5 \%$ to $35 \%$, the probability of failure is almost constant. This can be explaining by a weak change of the PDF of the factor of safety.

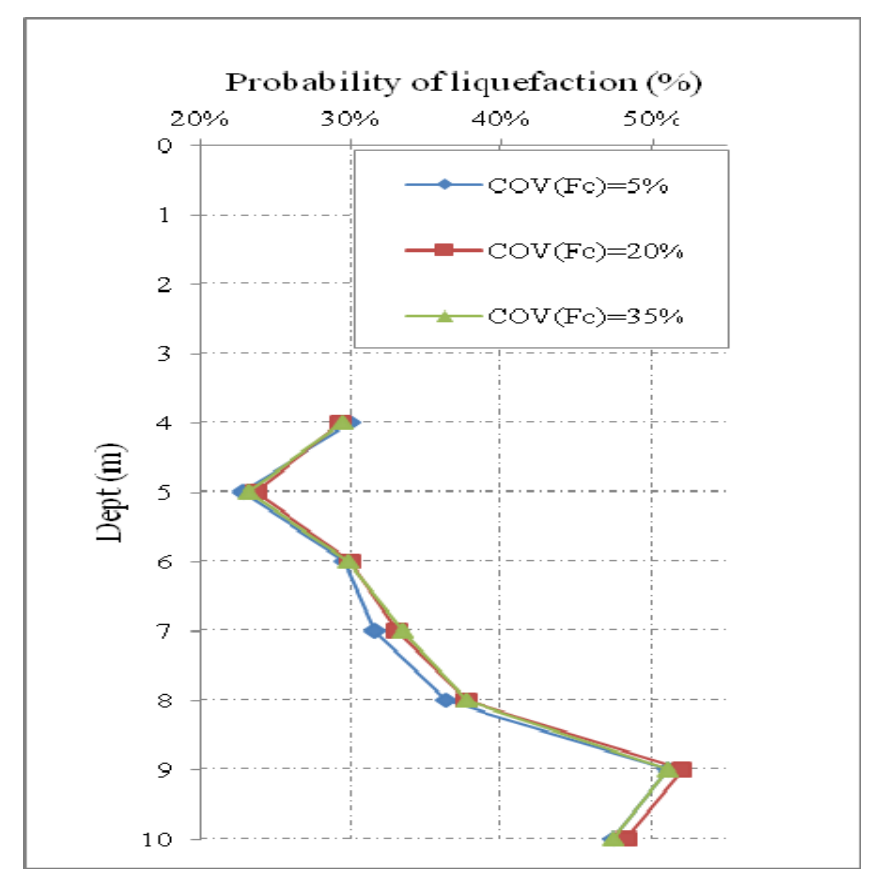

Figure 7. Effect of the coefficient of variation of fine contents 


\subsection{Effect of the Coefficient of Variation of CSR Parameters}

\subsubsection{Effect of $\mathrm{COV}(\mathrm{Mw}$ and Amax)}

Figure 8 shows the effect of the coefficient of variation of seismics parameters (the magnitude and the acceleration) on soil liquefaction probability.

This figure indicate that the effect of the coefficient of variation of the magnitude $\mathrm{M}_{\mathrm{W}}$ and maximum acceleration $\mathrm{a}_{\max }$ is less important than the COV of $\mathrm{N}_{1.60}$.

For the acceleration $\mathrm{a}_{\max }$ an increase in the $\operatorname{COV}\left(\mathrm{a}_{\max }\right)$ between 10 and $20 \%$ increases the probability of liquefaction between 2 and $5 \%$.

For the magnitude $\mathrm{M}_{\mathrm{W}}$, an increase in the $\operatorname{COV}\left(\mathrm{M}_{\mathrm{W}}\right)$ between 5 and $10 \%$ increases the probability of liquefaction to less than $2 \%$
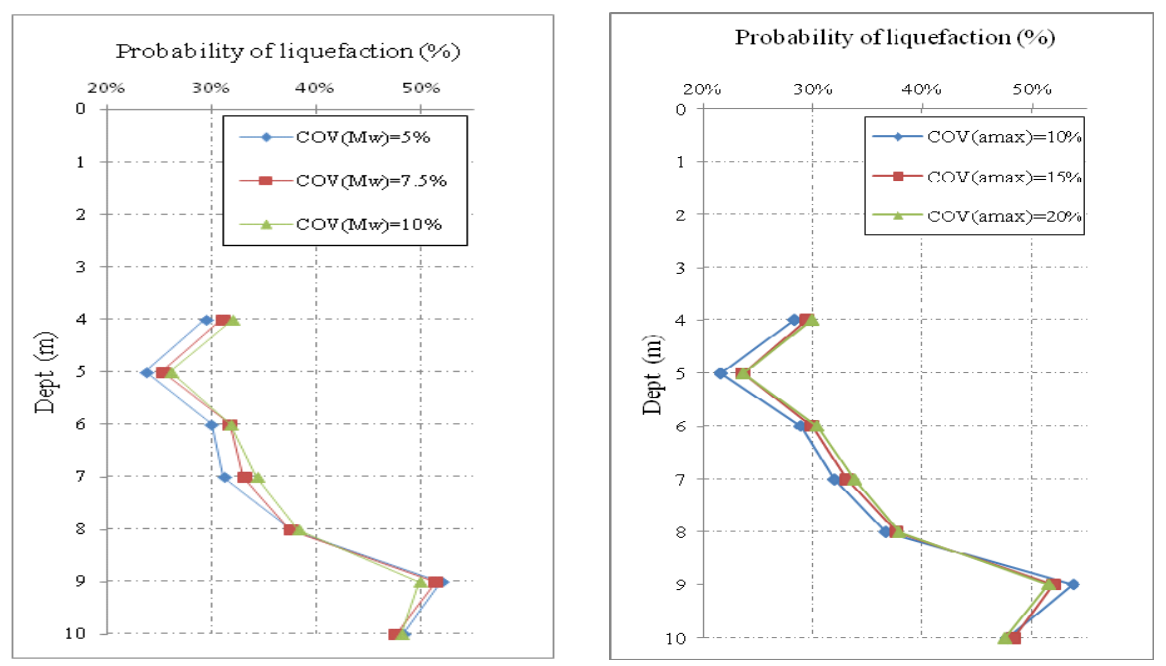

Figure 8. Effect of the coefficient of variation of seismic parameters on the probability of liquefaction

\subsubsection{Effect of the Coefficient of Variation of Total and Effective Stress}

We see very well through Figigure 9 that the coefficient of variation of the total and vertical effective stress has a negligible impact on the probability of liquefaction. Because of that, and for a reliability study of soil liquefaction potential, we can define these parameters by the mean values only without taking into account its variations.
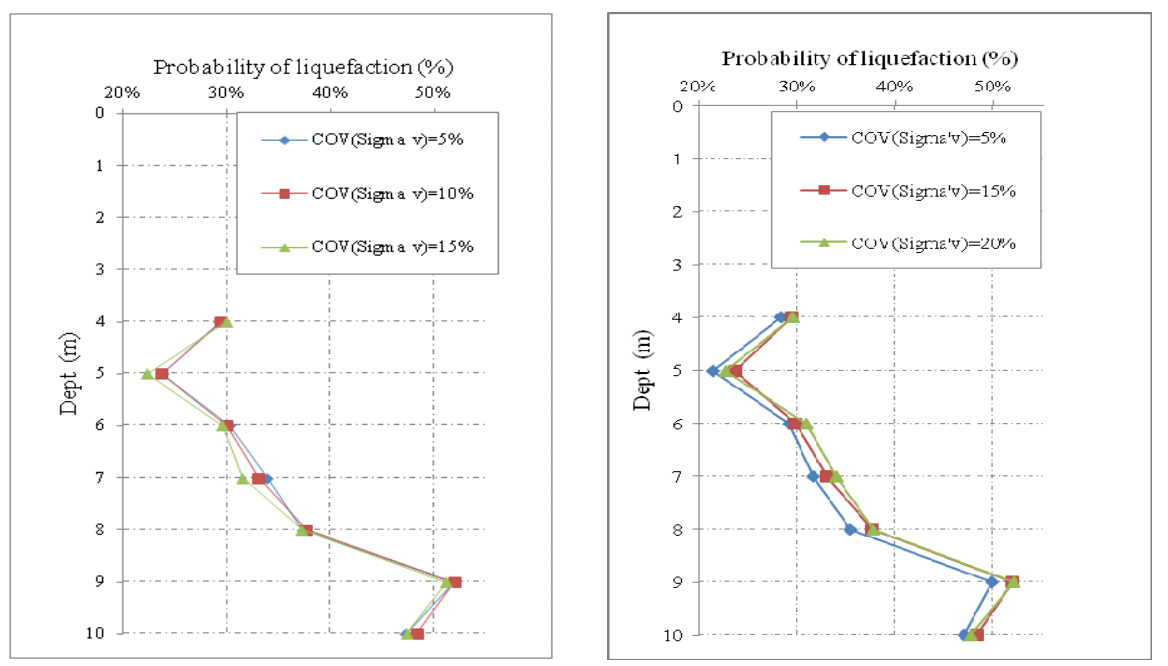

Figure 9. Effect of the coefficient of variation of different soil parameters on liquefaction probability 


\section{Conclusion}

In this paper we presented a reliability study of liquefaction potential of soil, it was found that the problem of liquefaction is probabilistic rather than deterministic because of different sources of uncertainty. Uncertainties we have treated are uncertainties due to the natural variability of the parameters of the performance function and of model uncertainties. The parameters used for the SPT test are modeled by random variables, and we applied the Monte Carlo simulation method to calculate the probability of liquefaction. The results show that MCS can predict the influence of stochastic parameters on the probability of liquefaction.

A sensitivity analysis based on the coefficient of variation has been presented, the results we found shows that the parameters that have the most influence on the liquefaction are: the number of counts N1.60, the magnitude of $\mathrm{Mw}$ earthquake and the maximum acceleration at surface $\mathrm{a}_{\max }$. By cons it was found that the coefficient of variation of the total stress and effective and the percentage of fines have no impact on the probability of liquefaction. For this we can define these three parameters by the mean value only.

The increase in the probability of liquefaction by increasing the coefficient of variation of the number of counts $\mathrm{N} 1.60$, the magnitude and the maximum acceleration shows that the probability of liquefaction is linear in terms of these variables.

\section{Reference}

Bhattacharya, S., \& Goda, K. (2013). Probabilistic buckling analysis of axially loaded piles in liquefiable soils. Soil Dynamics and Earthquake Engineering, 45, 13-24. http://dx.doi.org/10.1016/j.soildyn.2012.10.004

Cetin, K. O. (2000). Reliability-based assessment of seismic soil liquefaction initiation hazard (Doctoral dissertation). University of California, Berkeley, Calif.

Cetin, K. O., Seed, R. B., Der Kiureghian, A., Tokimatsu, K., Harder Jr, L. F., Kayen, R. E., \& Moss, R. E. (2004). Standard penetration test-based probabilistic and deterministic assessment of seismic soil liquefaction potential. Journal of Geotechnical and Geoenvironmental Engineering, 130(12), 1314-1340. http://dx.doi.org/10.1061/(ASCE)1090-0241(2004)130:12(1314)

Dai, S. H., \& Wang, M. O. (1992). Reliability Analysis in Engineering Applications. Van Nostrand Reinhold, New York.

Dobry, R., Martin, G. R., Parra, E., \& Bhattacharyya, A. (1982). Prediction of Pore Water Pressure Build up and Liquefaction of Sands during Earthquakes by the Cyclic Strain Method. National Bureau of Standards, Publication No. NBS- 138, Gaithersburg, MD.

Duncan, J. M. (2000). Factors of safety and reliability in geotechnical engineering. Journal of Geotechnical and Geoenvironmental Engineering, 307-316. http://dx.doi.org/10.1061/(ASCE)1090-0241(2000)126:4(307)

Griffiths, D. V., \& Fenton, G. A. (Eds.). (2007). Probabilistic methods in geotechnical engineering (Vol. 491). Springer.

Gutierrez, M., Duncan, J. M., Woods, C., \& Eddy, E. (2003). Development of a simplified reliability-based method for liquefaction evaluation (Final Technical Report, USGS Grant No. 02HQGR0058). Virginia Polytechnic Institute and State University.

Haldar, A., \& Tang, W. H. (1979). Probabilistic evaluation of liquefaction potential. Journal of the Geotechnical Engineering Division, 105(2), 145-163.

Idriss, I. M., \& Boulanger, R. W. (2006). Semi-empirical procedures for evaluating liquefaction potential during earthquakes. Soil Dynamics and Earthquake Engineering, 26(2), 115-130. http://dx.doi.org/10.1016/j.soildyn.2004.11.023

Idriss, I. M., \& Boulanger, R. W. (2010). SPT-based liquefaction triggering procedures. Center for Geotechnical Modeling, Department of Civil and Environmental Engineering, University of California Davis, California.

Johari, A., Javadi, A. A., Makiabadi, M. H., \& Khodaparast, A. R. (2012). Reliability assessment of liquefaction potential using the jointly distributed random variables method. Soil Dynamics and Earthquake Engineering, 38, 81-87. http://dx.doi.org/10.1016/j.soildyn.2012.01.017

Jones, A. L., Kramer, S. L., \& Arduino, P. (2002). Estimation of uncertainty in geotechnical properties for performance-based earthquake engineering. Pacific Earthquake Engineering Research Center, College of Engineering, University of California. 
Juang, C. H., Ching, J., Luo, Z., \& Ku, C. S. (2012). New models for probability of liquefaction using standard penetration tests based on an updated database of case histories. Engineering Geology, 133, 85-93. http://dx.doi.org/10.1016/j.enggeo.2012.02.015

Juang, C. H., Fang, S. Y., Li, D. L. (2008). Reliability analysis of liquefaction potential of soils using standard penetration test. Edited by Phoon, K. K, in Reliability-Based Design in Geotechnical Engineering.

Kulhawy, F. H. (1993). On the evaluation of static soil properties. In Stability and performance of slopes and Embankments II (pp. 95-115). ASCE.

Oka, L. G., Dewoolkar, M. M., \& Olson, S. M. (2012). Liquefaction assessment of cohesionless soils in the vicinity of large embankments. Soil Dynamics and Earthquake Engineering, 43, 33-44. http://dx.doi.org/10.1016/j.soildyn.2012.06.012

Law, K. T., Cao, Y. L., \& He, G. N. (1990). An energy approach for assessing seismic liquefaction potential. Canadian Geotechnical Journal, 27(3), 320-329. http://dx.doi.org/10.1139/t90-043

Liao, S. S., Veneziano, D., \& Whitman, R. V. (1988). Regression models for evaluating liquefaction probability. $\begin{array}{lllll}\text { Journal of } & \text { Geotechnical } & \text { Engineering, }\end{array}$ http://dx.doi.org/10.1061/(ASCE)0733-9410(1988)114:4(389)

Liao, S. S., \& Whitman, R. V. (1986). Overburden correction factors for SPT in sand. Journal of Geotechnical Engineering, 112(3), 373-377. http://dx.doi.org/10.1061/(ASCE)0733-9410(1986)112:3(373)

Moss, R. E. S. (2003). CPT Based Probabilistic Assessment of Seismic Soil Liquefaction Initiation (Doctoral dissertation). University of California, Berkeley.

Na, U. J., Ray Chaudhuri, S., \& Shinozuka, M. (2009). Effects of spatial variation of soil properties on seismic performance of port structures. Soil Dynamics and Earthquake Engineering, 29(3), 537-545. http://dx.doi.org/10.1016/j.soildyn.2008.06.002

Phoon, K. K., \& Kulhawy, F. H. (1999). Characterization of geotechnical variability. Canadian Geotechnical Journal, 36(4), 612-624. http://dx.doi.org/10.1139/t99-038

Popescu, R. (1995). Stochastic variability of soil properties data analysis, digital simulation, effects on system behavior (Doctoral dissertation). Princeton University.

Rezania, M., Faramarzi, A., \& Javadi, A. A. (2011). An evolutionary based approach for assessment of earthquake-induced soil liquefaction and lateral displacement. Engineering Applications of Artificial Intelligence, 24(1), 142-153. http://dx.doi.org/10.1016/j.engappai.2010.09.010

Salloum, T. (2008). Probabilistic assessments of soil liquefaction hazard (Doctoral thesis), Carleton University Ottawa, Ontario, Canada.

Seed, H. B., \& Idriss, I. M. (1971). Simplified procedure for evaluating soil liquefaction potential. Journal of the Soil Mechanics and Foundations Division, 97(9), 1249-1273.

Uzielli, M. (2004). Fuzzy modeling of CPT variability and probabilistic assessment of seismic liquefaction initiation (Doctoral dissertation). University of Florence, Italy.

Youd, T. L., \& Idriss, I. M. (2001). Liquefaction resistance of soils: summary report from the 1996 NCEER and 1998 NCEER/NSF workshops on evaluation of liquefaction resistance of soils. Journal of Geotechnical and Geoenvironmental Engineering, 127(4), 297-313. http://dx.doi.org/10.1061/(ASCE)1090-0241(2001)127:4(297)

\section{Copyrights}

Copyright for this article is retained by the author(s), with first publication rights granted to the journal.

This is an open-access article distributed under the terms and conditions of the Creative Commons Attribution license (http://creativecommons.org/licenses/by/3.0/). 